\title{
Article
}

\section{Design and Analysis of Trench-Assisted Low-Bending-Loss Large-Mode-Field-Area Multi-Core Fiber with an Air Hole}

\author{
Renjie Jia ${ }^{1,2}$, Yudong Lian ${ }^{1,2,3, *(1)}$, Yulei Wang ${ }^{1,2}$ and Zhiwei Lu ${ }^{1,2}$ \\ 1 Center for Advanced Laser Technology, Hebei University of Technology, Tianjin 300401, China; \\ 183975@stu.hebut.edu.cn (R.J.); wyl@hebut.edu.cn (Y.W.); zhiweilv@hebut.edu.cn (Z.L.) \\ 2 Hebei Key Laboratory of Advanced Laser Technology and Equipment, Tianjin 300401, China \\ 3 Tianjin Key Laboratory of Electronic Materials and Devices, Tianjin 300401, China \\ * Correspondence: ydlian@hebut.edu.cn
}

\section{check for}

updates

Citation: Jia, R.; Lian, Y.; Wang, Y.; $\mathrm{Lu}, \mathrm{Z}$. Design and Analysis of Trench-Assisted Low-Bending-Loss Large-Mode-Field-Area Multi-Core Fiber with an Air Hole. Photonics 2021, 8, 251. https://doi.org/ $10.3390 /$ photonics 8070251

Received: 19 May 2021

Accepted: 22 June 2021

Published: 30 June 2021

Publisher's Note: MDPI stays neutral with regard to jurisdictional claims in published maps and institutional affiliations.

Copyright: (c) 2021 by the authors. Licensee MDPI, Basel, Switzerland. This article is an open access article distributed under the terms and conditions of the Creative Commons Attribution (CC BY) license (https:// creativecommons.org/licenses/by/ $4.0 /)$.

\begin{abstract}
In this paper, a trench-assisted low-bending-loss large-mode-field-area multi-core fiber with air hole is proposed, which can achieve dual-mode transmission. The influence of structural parameters on fiber performance is analyzed systematically, and the structure of the trench, with a lower refractive index than the cladding, is also analyzed and optimized. By adjusting the structural parameters, the effective mode field area of the fundamental mode can reach $2003.24 \mathrm{um}^{2}$ at $1550 \mathrm{~nm}$, and when the bending radius is $1 \mathrm{~cm}$, the bending loss is $2.57 \times 10^{-3} \mathrm{~dB} / \mathrm{m}$. The practical implementation of the proposed fiber is feasible using existing fabrication technology and is applicable to the transmission of large-capacity optical communication systems and high-power lasers.
\end{abstract}

Keywords: dual-mode; low-bending-loss; trench-assisted; large-mode-field-area; multi-core fiber

\section{Introduction}

The advent of the "Internet +" era and the 5G era have put forward higher requirements for the high speed and high bandwidth of optical communication networks. Ultrahigh-speed, large-capacity, and ultra-long-distance transmission has become the future trend. The conventional single-mode single-core fiber (SM-SCF) is gradually approaching its $100 \mathrm{~Tb} / \mathrm{s}$ transmission limit due to the limitation of the nonlinear effect [1]. The rapid development of communication technologies such as wavelength division multiplexing (WDM) and polarization multiplexing (PDM) enables mode division multiplexing (MDM) based on few-mode fibers to be used to increase channel transmission capacity [2]. Increasing the mode field area can reduce the nonlinear effect of the fiber, but it will also increase the number of transmittable modes in the fiber and bring about bending loss. Therefore, low-bending loss and large-mode area few-mode fibers have important research significance in high-power optical communication devices [3].

In recent years, fiber lasers have developed rapidly. In order to overcome the limitation of fiber laser power improvements such as the fiber nonlinear effect and fiber damage, the method of increasing the mode field area can be used to overcome the nonlinear effect. The strong coupling multi-core fiber (MCF) increases the mode field area (MFA) of the fiber by introducing the lateral coupling of the core, thereby reducing the nonlinear effect. Therefore, it is often used in fiber lasers and amplifiers [4]. But multi-core fibers have a higher bending loss [5]. However, the reduction of the bending loss (BL) is conducive to improving the stability and output efficiency of the fiber laser source [6,7]. Adding air holes and a trench in cladding can effectively reduce the bending loss.

Commonly used fiber structures for achieving a large mode field and low bending loss include: photonic crystal fiber, trench-assisted fiber, and multi-core fiber. The photonic crystal fiber has a large mode field area and good bending resistance. However, the structure is complex and asymmetric, and the technological level is high and welding is difficult. Usually, the effective mode field area can reach $794 \mathrm{um}^{2}$, and the bending 
loss is $0.064 \mathrm{~dB} / \mathrm{m}$, when the bending radius is $15 \mathrm{~cm}$ [8]. The trench-assisted fiber has good bending resistance. However, due to process limitations, the width and depth of the submerged layer will be limited. The fiber can not only support ultra-low bending loss $(0.052 \mathrm{~dB} /$ turn when bending radius $\mathrm{R}=5 \mathrm{~mm})$, but also support an effective mode field area of up to $260 \mathrm{um}^{2}$ at a working wavelength of $1.55 \mathrm{um}[9,10]$.

Multi-core optical fiber has the characteristics of a symmetrical structure distribution, simple design, flexible parameter adjustment, and large mode field area. However, large mode field multi-core optical fiber often has a higher bending loss. The fiber can generally transmit with a low bending loss (less than $1.0 \mathrm{~dB} / \mathrm{m}$ when the bending radius $\mathrm{R}=0.34 \mathrm{~m}$ ), and the effective area is as high as $1331 \mathrm{um}^{2}$ [11-15].

There is a mutually restrictive relationship between the bending loss of the optical fiber and the mode field diameter (mode field area). The smaller the mode field diameter, the better the light can be confined, thus reducing the bending loss of the fiber. But if the mode field diameter of the fiber is too small, there will be serious nonlinear effects under high power conditions [16]. Therefore, the two must be considered comprehensively.

A trench-assisted low-bending-loss large-mode-field-area multi-core fiber (TA-LBLLMFA MCF) with an air hole structure is proposed in this paper that can realize dual-mode transmission. The MFA of the fundamental mode of the fiber can reach $2003.24 \mathrm{um}^{2}$. When the bending radius is $1 \mathrm{~cm}$, BL can be as low as $2.57 \times 10^{-3} \mathrm{~dB} / \mathrm{m}$. Using the existing fabrication techniques, the practical implementation of the proposed fiber is feasible.

\section{Optical Fiber Structure and Theoretical Analysis}

The fiber structure is shown in Figure 1. The yellow part is the central core and the gray part is the silica cladding. The blue part is a trench with a lower refractive index (RI) than the cladding. This structure adds 10 cores (green part) to the traditional hexagonal 19-core optical fiber structure (pink part), removes the cores on both sides of the 19-core optical fiber, and adds air holes and a trench in the cladding. The green part, yellow part, and pink part constitute the core area.

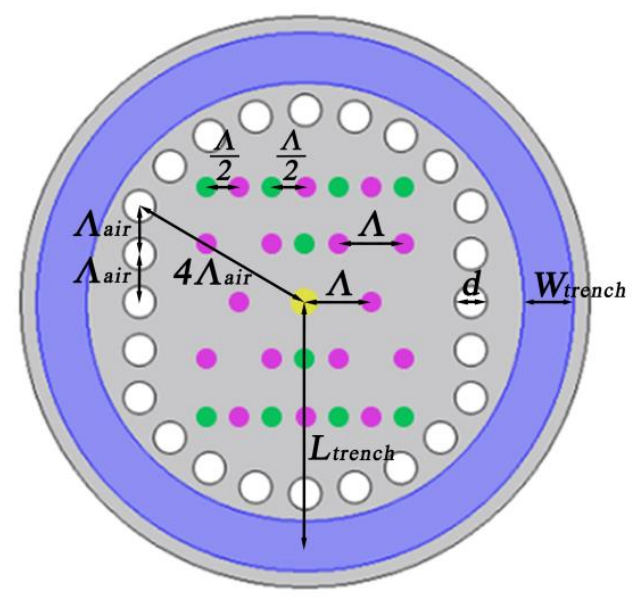

Figure 1. Schematic diagram of optical fiber cross section.

The diameter of the fiber cladding is $d_{\text {clad }}=125 \mathrm{um}$, the refractive index of the fiber cladding $n_{\text {clad }}=1.444$, the refractive index of the air hole is the refractive index of air $n_{\text {air }}=1.000$, the refractive index of the central core is $n_{\text {center, }}$, and the refractive index of the other cores is $n_{\text {core. }}$ The refractive index difference between the center core and the cladding is $\Delta n_{\text {center }}=n_{\text {center }}-$ $n_{\text {clad }} ; \Delta n=n_{\text {core }}-n_{\text {clad }}$ is the refractive index difference between the core and the cladding; $\Lambda$ is the distance between the core and the core, $\Lambda_{\text {air }}=14 \mathrm{um}$ is the spacing between the air holes, and $d_{\text {center }}$ is the diameter of the central core. The diameter of the other cores is $\mathrm{d}$, the diameter of the air hole is $d_{\text {air }}=7 \mathrm{um}$, and the refractive index of the trench is $n_{\text {trench }} . \Delta n_{1}=n_{\text {clad }}-n_{\text {trench }}$, which is the refractive index difference between cladding and the trench; $W_{\text {trench }}$ is the thickness of the trench layer, and $L_{\text {trench }}$ is the distance between the trench layer and the central core. The 
structural parameters are composed of seven parameters: $\Lambda, d, \Delta n, d_{\text {center }}, \Delta n_{\text {cneter }}, W_{\text {trench }}$, and Ltrench.

This paper is mainly based on the finite element method (FEM) software to analyze the fiber structure [17].

The refractive index of the beam propagating in a specific mode changes with the wavelength and the geometric structure of the waveguide. This is called the effective refractive index $n_{\text {eff }}$ of the mode. The conduction of specific mode in optical fiber needs to satisfy the conduction mode condition of the optical waveguide theory: $n_{\text {eff }}<n_{\text {clad }}<n_{\text {core }}$. Otherwise, the mode will be cut off and does not exist in the fiber. The effective refractive index $n_{\text {eff }}$ calculation formula can be expressed as [18]:

$$
n_{e f f}=\operatorname{Re}\left(\frac{\beta}{k_{0}}\right) \text {. }
$$

Among these figures, $\beta$ is the propagation constant, the $R e$ is the real part of the whole, the wave number in vacuum is $k_{0}=2 \pi / \lambda$, and $\lambda$ is the working wavelength.

The electromagnetic field of each mode along the cross section of the fiber is called the mode field. An optical fiber with a large mode field area can suppress the nonlinear effect in the optical fiber. The effective mode field area $A_{\text {eff }}$ can be expressed as [19]:

$$
A_{e f f}=\frac{\int\left(E E^{*} d A\right)^{2}}{\int\left(E E^{*}\right)^{2} d A}
$$

where $E$ represents the electric field of the mode, and $E^{*}$ represents the conjugate complex number of the electric field of the mode.

When the fiber is bent in the positive direction of the x-axis, and the equivalent refractive index distribution of the fiber cross-section is [20]:

$$
n(x, y)=n_{0}(x, y) \sqrt{1+\frac{2 x}{R_{e f f}}} .
$$

Among them, $n(x, y)$ is the equivalent refractive index of the fiber after bending, and $n_{0}(x, y)$ is the initial refractive index of the fiber. $R$ is the bending radius of the optical fiber along the positive $x$-axis. When the elastic optical correction factor is introduced, the equivalent bending radius $R_{\text {eff }}=1.28 R$.

The calculation formula of fiber bending loss $\alpha$ can be expressed as [20]:

$$
a=-\frac{20 \pi}{\ln 10} \operatorname{IM}(\beta) \approx-8.686 \frac{2 \pi}{\lambda} \operatorname{IM}\left(n_{\text {eff }}\right)
$$

where $I M$ represents the imaginary part, and $n_{\text {eff }}$ represents the effective refractive index of the fiber.

\section{Analysis and Optimization of Optical Fiber Structure Parameters}

The fiber structure can effectively destroy the circular symmetrical structure of the traditional 19-core optical fiber. It cuts off the higher-order modes $\left(\mathrm{TE}_{01}, \mathrm{TM}_{01}\right)$, leaving two degenerate fundamental modes $\left(\mathrm{HE}_{11}\right)$ and second-order modes $\left(\mathrm{HE}_{21}\right)$, as shown in Figure 2. In addition, the 10 fiber cores increase the lateral coupling of the fiber, which significantly increases the mode field area of the fiber. The effective refractive index of the cladding is reduced by adding air holes and grooves in the cladding. As a result, the refractive index difference between the core and the cladding is increased, and the BL is significantly reduced. 


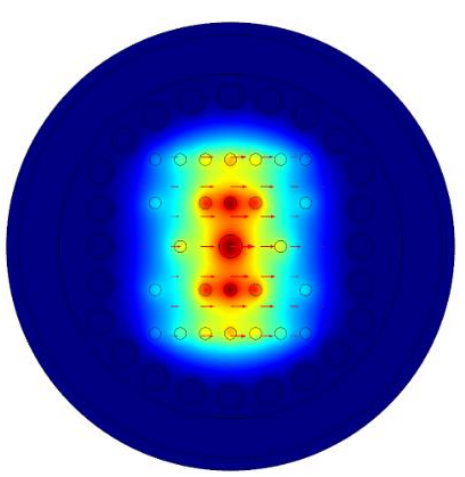

(a)

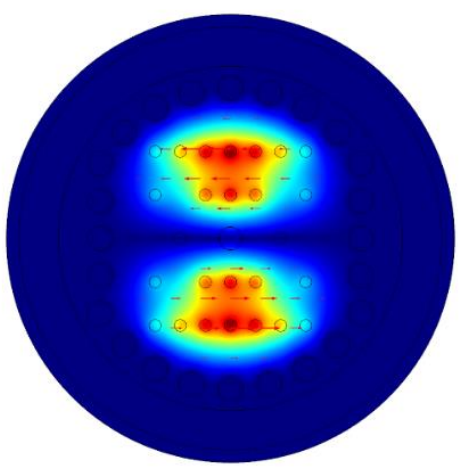

(c)

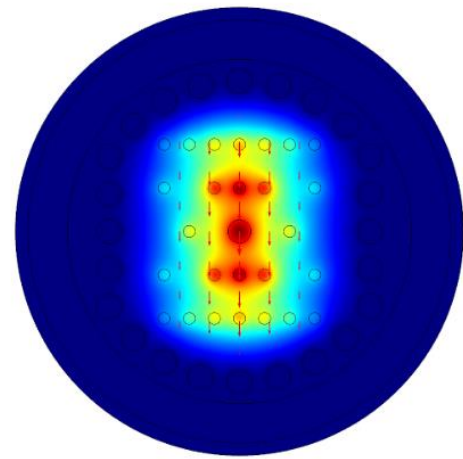

(b)

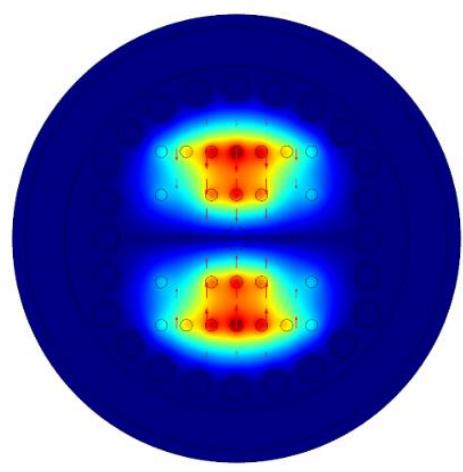

(d)

Figure 2. Optical fiber two-dimensional mode field and electric field distribution diagram: (a) $\mathrm{HE}_{11-\mathrm{x}}$ mode; (b) $\mathrm{HE}_{11-\mathrm{y}}$ mode; (c) $\mathrm{HE}_{21-\mathrm{x}}$ mode; (d) $\mathrm{HE}_{21-\mathrm{y}}$ mode.

\subsection{Analysis of Three Structural Parameters $\Lambda, d$, and $\Delta n$}

For this paper, we conducted research on the basis of strict dual-mode transmission. $\Lambda, d$, and $\Delta n$ three structural parameters were analyzed. The working wavelength $\lambda$ was set at $1550 \mathrm{~nm}$, and the initial structure parameter was set as $\Lambda=15 \mathrm{um}, d=3 \mathrm{um}, \Delta n=0.003$, $d_{\text {center }}=d, \Delta n_{\text {center }}=0.003, W_{\text {trench }}=5.5 \mathrm{um}, L_{\text {trench }}=52 \mathrm{um}, \Delta n_{1}=0.004$.

The result of analyzing the influence of the structural parameter $\Lambda$ on $n_{\text {eff }}$ and $A_{\text {eff }}$ is shown in Figure 3. To realize dual-mode transmission and cut high-order modes of optical fiber, its effective refractive index should be less than $n_{\text {clad }}$. Figure 3 a shows that the transmission mode can be adjusted by modifying $\Lambda$. If dual-mode transmission is to be realized, $\Lambda$ should be greater than or equal to $11.5 \mathrm{um}$. Figure $3 \mathrm{~b}$ shows that as $\Lambda$ goes from $10 \mathrm{um}$ to $15 \mathrm{um}$, the $A_{\text {eff }}$ of $\mathrm{HE}_{11}$ grows from $1451 \mathrm{um}^{2}$ to $2201 \mathrm{um}^{2}$ and then drops to $1996 \mathrm{um}^{2}$, and finally reaches the maximum value at $14.5 \mathrm{um}$; in addition, the $A_{\text {eff }}$ of $\mathrm{HE}_{21}$ grows from $1219 \mathrm{um}^{2}$ to $1717 \mathrm{um}^{2}$. From the above discussion, it can be concluded that $14.5 \mathrm{um}$ is the best choice for $\Lambda$. 


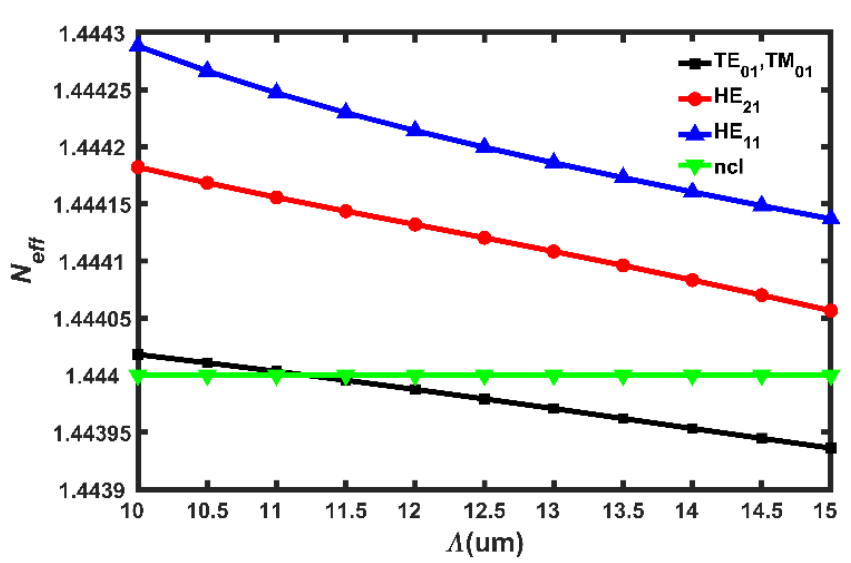

(a)

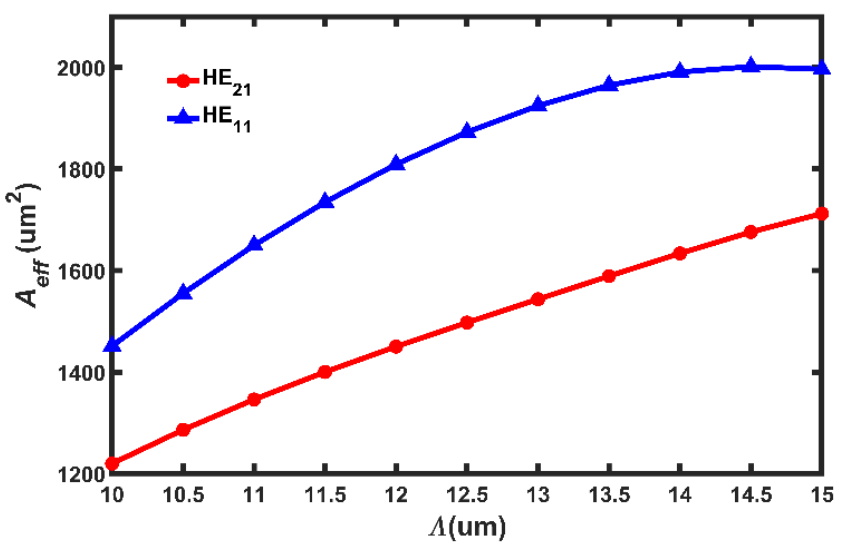

(b)

Figure 3. (a) The variation of $N_{\text {eff }}$ with $\Lambda$ for each mode; (b) The change of $A_{\text {eff }}$ of $\mathrm{HE}_{11}$ and $\mathrm{HE}_{21}$ with $\Lambda$.

When $\Lambda$ is $14.5 \mathrm{um}$, the results of analyzing the influence of structure parameter $\mathrm{d}$ on $n_{\text {eff }}$ and $A_{\text {eff }}$ are shown in Figure 4. Figure 4a shows that as d increases, the effective refractive index of each mode also increases. If $d$ is less than or equal to $3.3 \mathrm{um}$, then the fiber realizes dual-mode transmission. It can be seen from Figure $4 \mathrm{~b}$ that as $\mathrm{d}$ increases to $3.4 \mathrm{um}$, the $A_{\text {eff }}$ of $\mathrm{HE}_{11}$ rises to the maximum value of $2032 \mathrm{um}^{2}$, and the $A_{\text {eff }}$ of $\mathrm{HE}_{21}$ decreases from $1706 \mathrm{um}^{2}$ to $1616 \mathrm{um}^{2}$. However, due to the limitation of dual-mode transmission conditions, $\mathrm{d}$ is the most suitable to be $3.3 \mathrm{um}$. At this time, the $A_{\text {eff }}$ of $\mathrm{HE}_{11}$ is $2029 \mathrm{um}^{2}$, and the $A_{\text {eff }}$ of $\mathrm{HE}_{21}$ is $1632 \mathrm{um}^{2}$. Optical fiber can achieve dual-mode transmission, but also has a large $A_{\text {eff. }}$.

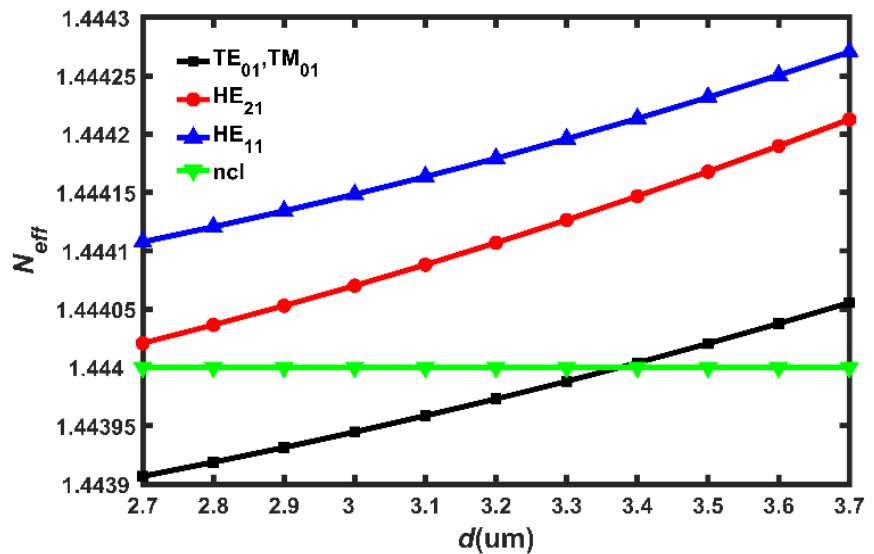

(a)

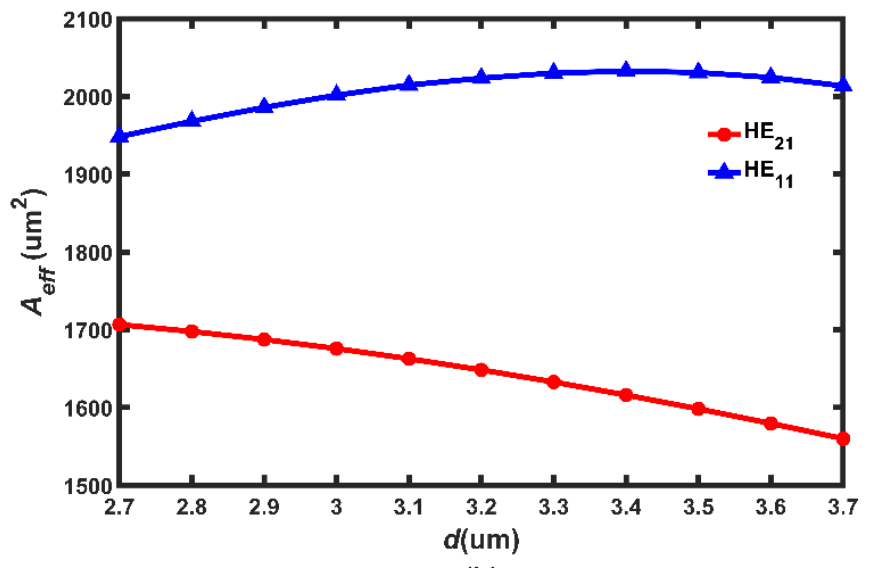

(b)

Figure 4. (a) Variation of $N_{\text {eff }}$ with $d$ for each mode; (b) the change of $A_{e f f}$ of $\mathrm{HE}_{11}$ and $\mathrm{HE}_{21}$ with $d$.

When $d$ is $3.3 \mathrm{um}$, the effect of $\Delta n$ on $n_{\text {eff }}$ and $A_{\text {eff }}$ is shown in Figure 5. Figure 5a shows that with the increase of $\Delta n$, the neff of $\mathrm{TE}_{01}$ and $\mathrm{TM}_{01}$ also increase. In order to ensure dual-mode transmission, $\Delta n$ should be less than or equal to 0.00315 . It can be seen from Figure $5 \mathrm{~b}$ that the maximum $A_{\text {eff }}$ of $\mathrm{HE}_{11}$ at $3.1 \mathrm{um}$ is $2031 \mathrm{um}^{2}$ for $\Delta n$, and the $A_{\text {eff }}$ of $\mathrm{HE}_{21}$ at this time is $1622 \mathrm{um}^{2}$. In order to ensure that the fundamental mode obtains a larger mode field area, $\Delta n$ is selected as 0.003 . 


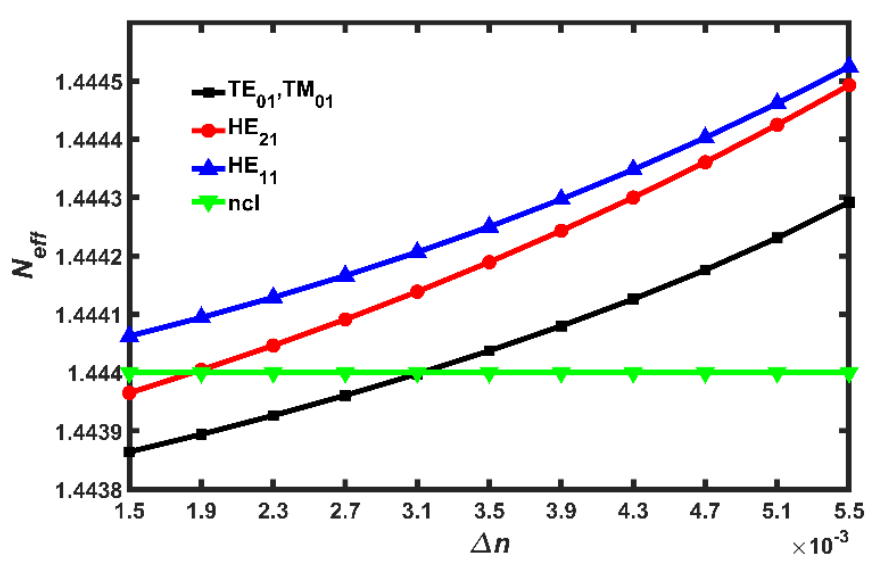

(a)

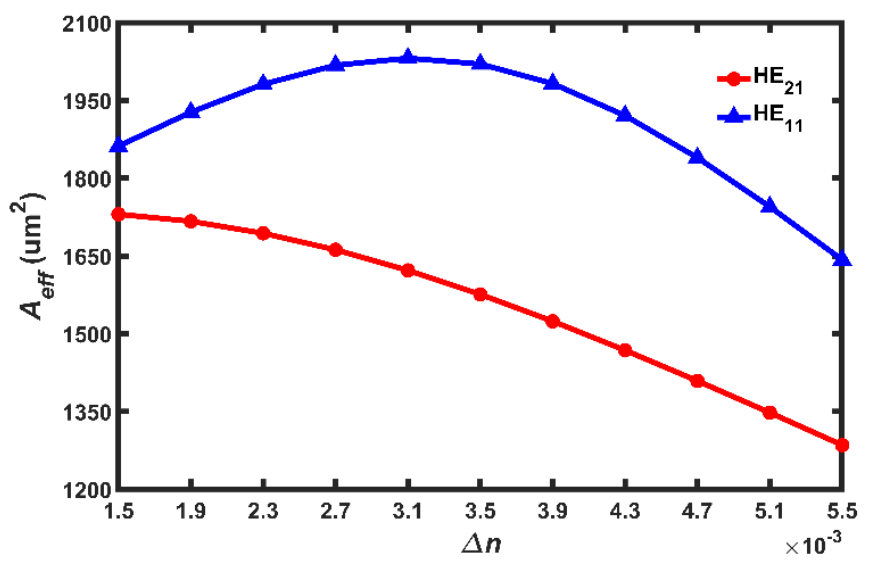

(b)

Figure 5. (a) The $n_{\text {eff }}$ of each mode varies with $\Delta n$; (b) the change of $A_{\text {eff }}$ of $\mathrm{HE}_{11}$ and $\mathrm{HE}_{21}$ with $\Delta n$.

\subsection{Analysis of Structural Parameters of Central Core}

In order to enhance the core's ability to confine light, the central core diameter $d_{\text {center }}$ is increased to reduce the central core refractive index $\Delta n_{\text {center }}$, thereby reducing the bending loss. This part analyzes the $d_{\text {center }}$ and $\Delta n_{\text {center }}$ structure parameters of the center core and initializes the center core structure parameters to $\Delta n_{\text {center }}=0.001$ and $d_{\text {center }}=3 \mathrm{um}$.

Based on the optimization of the above structural parameters, the influence of $d_{\text {center }}$ on $n_{\text {eff }}$ and $A_{\text {eff }}$ is studied, as shown in Figure 6. Figure 6a shows that the effective refractive index of the higher-order modes $\mathrm{TE}_{01}, \mathrm{TM}_{01}$ is around 1.444, intersecting with $n c l$ at $7.2 \mathrm{um}$. To ensure dual-mode transmission, $d_{\text {center }}$ should be less than $7.2 \mathrm{um}$. As shown in Figure $6 \mathrm{~b}, \mathrm{HE}_{11}$ has the largest $A_{\text {eff }}$ at $4.8 \mathrm{um}$ in $d_{\text {center }}$, which is about $2039 \mathrm{um}^{2}$ and the $A_{\text {eff }}$ of $\mathrm{HE}_{21}$ has been stable around $1622 \mathrm{um}^{2}$, so $4.8 \mathrm{um}$ is the best choice for $d_{\text {center }}$.

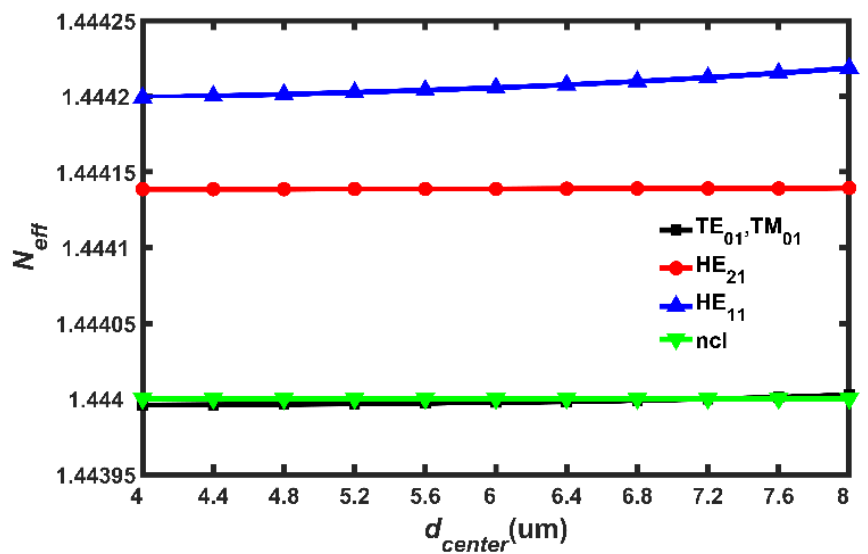

(a)

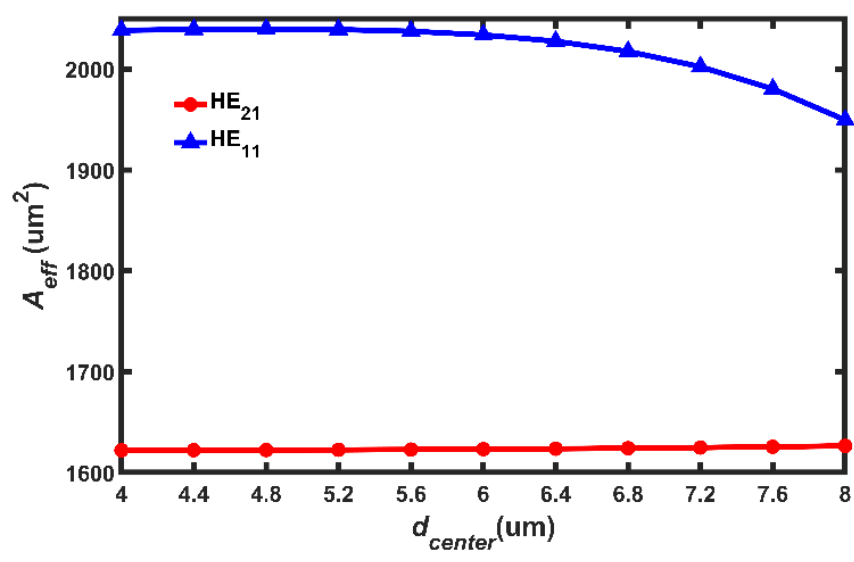

(b)

Figure 6. (a) The $N_{\text {eff }}$ of $\mathrm{HE}_{11}$ and $\mathrm{HE}_{21}$ varies with $d_{\text {center; }}$ (b) The change of $A_{\text {eff }}$ of $\mathrm{HE}_{11}$ and $\mathrm{HE}_{21}$ with $d_{\text {center }}$.

When the $d_{\text {center }}$ is $4.8 \mathrm{um}$, the influence of $\Delta n_{\text {center }}$ on $n_{\text {eff }}$ and $A_{\text {eff }}$ is shown in Figure 7. Figure 7a shows that $\mathrm{TE}_{01}, \mathrm{TM}_{01}$, and ncl intersect at 0.002 . To ensure dual-mode transmission, $\Delta n_{\text {center }}$ must be restricted within 0.002 . 


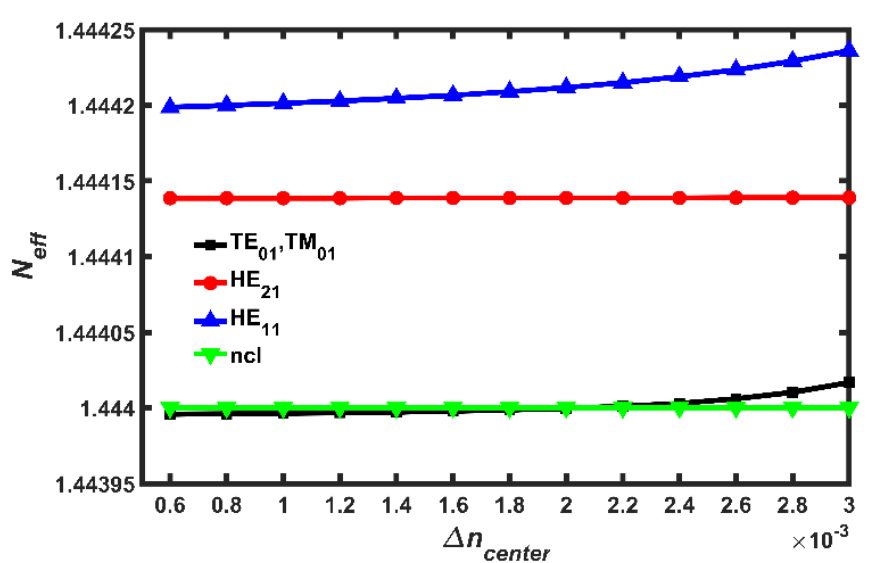

(a)

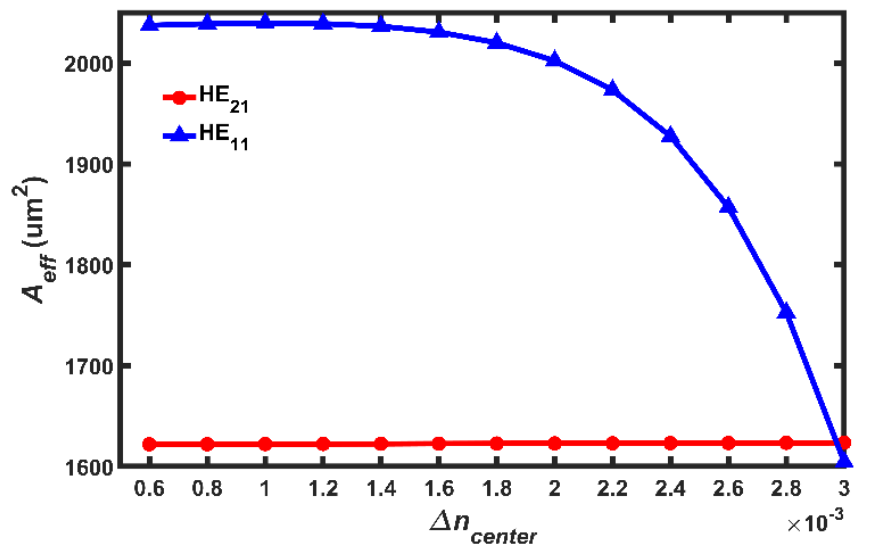

(b)

Figure 7. (a) The $N_{\text {eff }}$ of $\mathrm{HE}_{11}$ and $\mathrm{HE}_{21}$ varies with $\Delta n_{\text {center }}$ (b) the change of $A_{\text {eff }}$ of $\mathrm{HE}_{11}$ and $\mathrm{HE}_{21}$ with $\Delta n_{\text {center }}$.

The greater the refractive index of the central core of the optical fiber, the stronger its ability to confine light, but the mode field area will decrease. It can be seen from Figure $7 \mathrm{~b}$ that when $\Delta n_{\text {center }}$ exceeds 0.002 , the $A_{\text {eff }}$ of $\mathrm{HE}_{11}$ decreases rapidly. The $A_{\text {eff }}$ of $\mathrm{HE}_{21}$ is stable at $1622 \mathrm{um}^{2}$, and the $A_{\text {eff }}$ of $\mathrm{HE}_{11}$ is $2002 \mathrm{um}^{2}$ at 0.002 . $\Delta n_{\text {center }}$ is selected as 0.002 as the best, which not only has a large mode field area, but also has a better ability to bind light.

\section{Bending Characteristic Analysis}

This part studies the effect of $R$ on the $A_{\text {eff }}$ and $B L$ of $\mathrm{HE}_{11}$ and $\mathrm{HE}_{21}$ when the working wavelength is $1550 \mathrm{~nm}$.

When the bending radius is $1.5 \mathrm{~cm}$, the mode field and electric field will deviate from the core area to the direction of the trench as shown in Figure 8, resulting in a reduction in the mode field area and an increase in the bending loss. In order to prevent the electric field from deviating to the trench, a circle of air holes is added in the middle of the cladding. The air holes have a lower refractive index, which can effectively prevent the electric field from deviating to the trench. At the same time, it reduces the refractive index of the cladding and the bending loss is reduced.

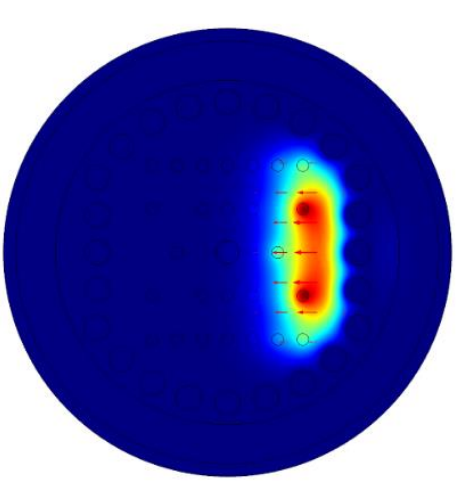

(a)

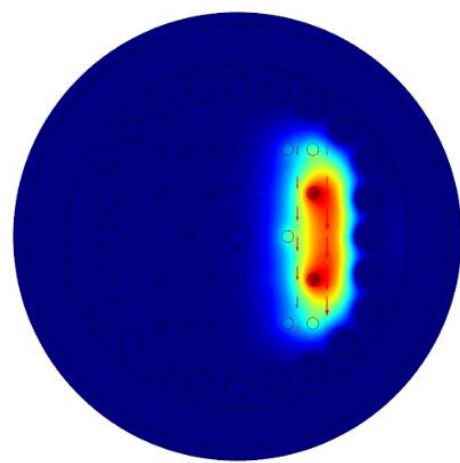

(b)

Figure 8. Cont. 


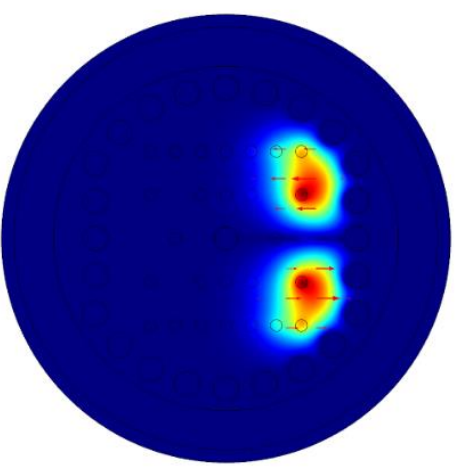

(c)

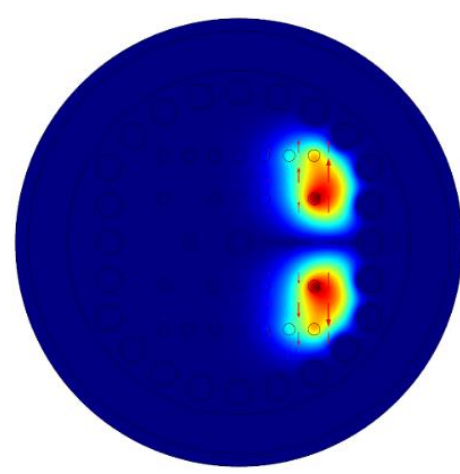

(d)

Figure 8. The two-dimensional mode field and electric field distribution diagram of the fiber when the bending radius is $1.5 \mathrm{~cm}$ : (a) $\mathrm{HE}_{11-\mathrm{x}}$ mode; (b) $\mathrm{HE}_{11-\mathrm{y}}$ mode; (c) $\mathrm{HE}_{21-\mathrm{x}}$ mode; (d) $\mathrm{HE}_{21-\mathrm{y}}$ mode.

The two polarization states of a mode have the same changing trend and similar size, so the two polarization states are almost overlapped. Figure 9a shows that when $\mathrm{R}$ increases from $1 \mathrm{~cm}$ to $19 \mathrm{~cm}$, the $A_{\text {eff }}$ of $\mathrm{HE}_{11}$ and $\mathrm{HE}_{21}$ will also increase. After the bending radius is greater than $11 \mathrm{~cm}$, the $A_{\text {eff }}$ of $\mathrm{HE}_{11}$ and $\mathrm{HE}_{21}$ tends to be stable, around $2100 \mathrm{um}^{2}$ and $1600 \mathrm{um}^{2}$. Figure $9 \mathrm{~b}$ shows that as $R$ increases from $1 \mathrm{~cm}$ to $6 \mathrm{~cm}$, the $B L$ of $\mathrm{HE}_{11}$ and $\mathrm{HE}_{21}$ will also decrease. When the bending radius is $1.5 \mathrm{~cm}$, the $B L$ of the two modes is less than $10^{-3} \mathrm{~dB} / \mathrm{m}$. The fiber has very low bending loss. In the case of no bending, the $A_{\text {eff }}$ of $\mathrm{HE}_{11}$ is $2003.24 \mathrm{um}^{2}$ and the $A_{\text {eff }}$ of $\mathrm{HE}_{21}$ is $1686.71 \mathrm{um}^{2}$. Therefore, the optical fiber has good bending insensitivity.

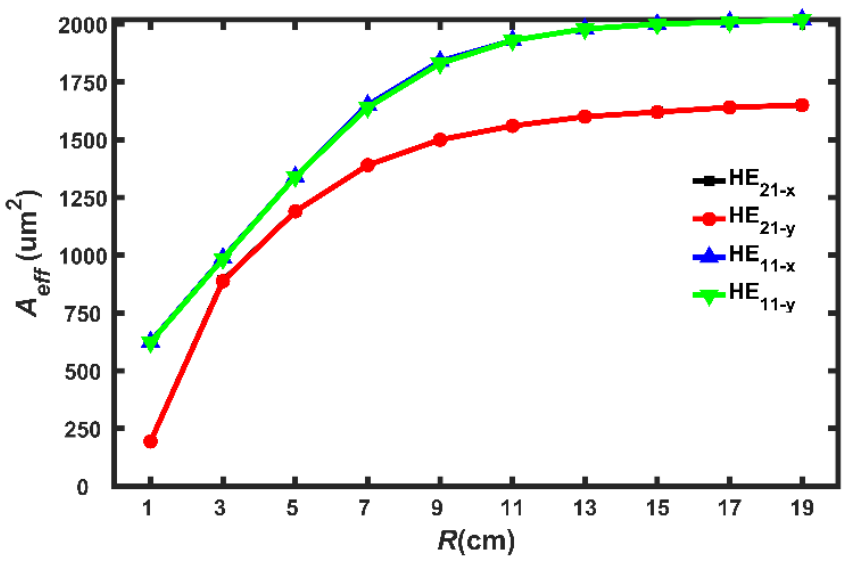

(a)

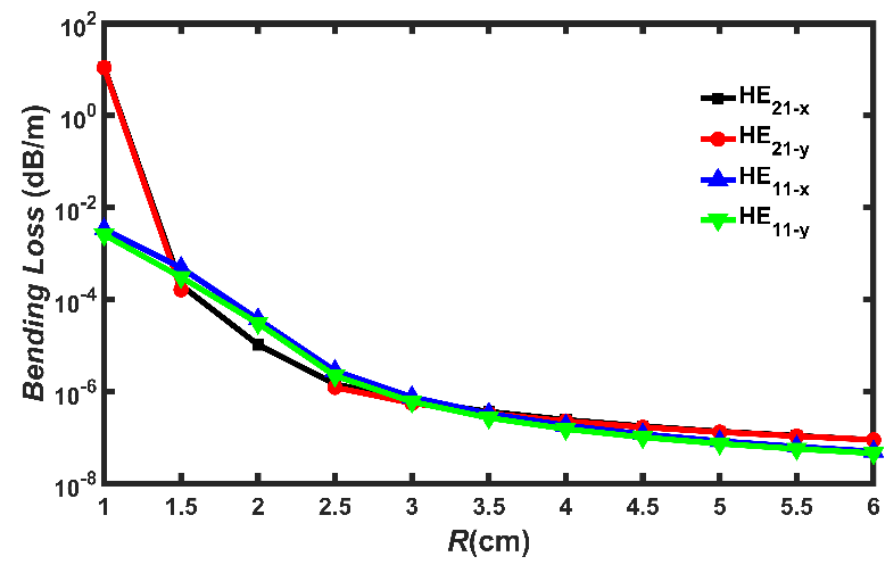

(b)

Figure 9. (a) The change of $A_{\text {eff }}$ of $\mathrm{HE}_{11}$ and $\mathrm{HE}_{21}$ with $R$; (b) the $B L$ of $\mathrm{HE}_{11}$ and $\mathrm{HE}_{21}$ changes with $R$.

Table 1 is a comparison table between this article and other recent work and literature.

Table 1. A comparison table with other recent work and literature.

\begin{tabular}{|c|c|}
\hline Article & Description \\
\hline [21] & $\begin{array}{l}\text { Mode area of } 2622 \mathrm{um}^{2} \text { at a bend radius of } 20 \mathrm{~cm} \text { can be achieved. Bending loss can be reduced to } \\
\text { about } 0.092 \mathrm{~dB} / \mathrm{m} \text { at } 1550 \mathrm{~nm} \text {. }\end{array}$ \\
\hline [17] & $\begin{array}{l}\text { When the bending radius is } 20 \mathrm{~cm} \text {, the effective mode area of the fiber can reach } 914 \mathrm{um}^{2} \text { at } 1.06 \mathrm{um} \text {, } \\
\text { and loss ratio between lowest-HOMs and fundamental mode is larger than } 100 \text {. }\end{array}$ \\
\hline [22] & $\begin{array}{l}\text { Mode field area of the fundamental mode can reach } 1916.042 \mathrm{um}^{2} \text { at } 1550 \mathrm{~nm} \text {., and when the } \\
\text { bending radius is } 1.4 \mathrm{~cm} \text {, the bending loss is } 2.96 \times 10^{-3} \mathrm{~dB} / \mathrm{m} \text {. }\end{array}$ \\
\hline This article & $\begin{array}{l}\text { Mode field area of the fundamental mode can reach } 2003.24 \mathrm{um}^{2} \text {, and when the bending radius is } \\
1 \mathrm{~cm} \text {, the bending loss is } 2.57 \times 10^{-3} \mathrm{~dB} / \mathrm{m} \text { at } 1550 \mathrm{~nm} \text {. }\end{array}$ \\
\hline
\end{tabular}




\section{Structural Optimization of the Trench}

Adding trench in the cladding can effectively reduce the bending loss of the optical fiber and improve the bending resistance of the optical fiber. However, the bending loss of the optical fiber and the mode field area are mutually restrictive, so the two parts must be taken into consideration at the same time in the design. In order to balance the relationship between the bending loss and the mode field area, this paper defines the performance factor PI [23] of the fiber, and the expression is:

$$
P I=\frac{B L}{A_{e f f}} .
$$

$P I$ is used to measure the trade-off between $B L$ and $A_{\text {eff. }}$. When $A_{\text {eff }}$ increases and $B L$ decreases, $P I$ will decrease, and the comprehensive performance of the fiber will be better.

This section provides analysis and optimization of the $L_{\text {trench }}$ and $\Delta n_{1}$ parameters of the trench. We used PI to evaluate the comprehensive performance of the optical fiber. $W_{\text {trench }}$ has little effect on the $A_{\text {eff }}$ of each mode, and the larger the thickness, the smaller the bending loss. Therefore, the larger the $W_{\text {trench }}$, the better the comprehensive performance of the fiber. However, $W_{\text {trench }}$ is limited by the diameter of the cladding layer to a maximum of $5.5 \mathrm{um}$.

When the $W_{\text {trench }}$ is $5.5 \mathrm{um}$, the influence of the $L_{\text {trench }}$ on the $A_{\text {eff }}$ and $P I$ of the fiber under the condition of a $1.5 \mathrm{~cm}$ bending radius is shown in Figure 10. From Figure 10a, it can be seen that the $A_{\text {eff }}$ of $\mathrm{HE}_{11}$ drops rapidly at $53.9 \mathrm{um}$, and the $A_{\text {eff }}$ of $\mathrm{HE}_{21}$ slightly rises. When the $L_{\text {trench }}$ exceeds $53.8 \mathrm{um}$, the trench will exceed the cladding and the structure will be disordered, resulting in a sudden change in the curve. It can be seen from Figure $10 \mathrm{~b}$ that with the increase of $L_{\text {trench }}$, the $P I$ of $\mathrm{HE}_{11}$ first drops and then rises rapidly, with a minimum value at $53.8 \mathrm{um}$, while the PI of $\mathrm{HE}_{21}$ is relatively stable. So, at $53.8 \mathrm{um}$, the fiber has the best comprehensive performance.

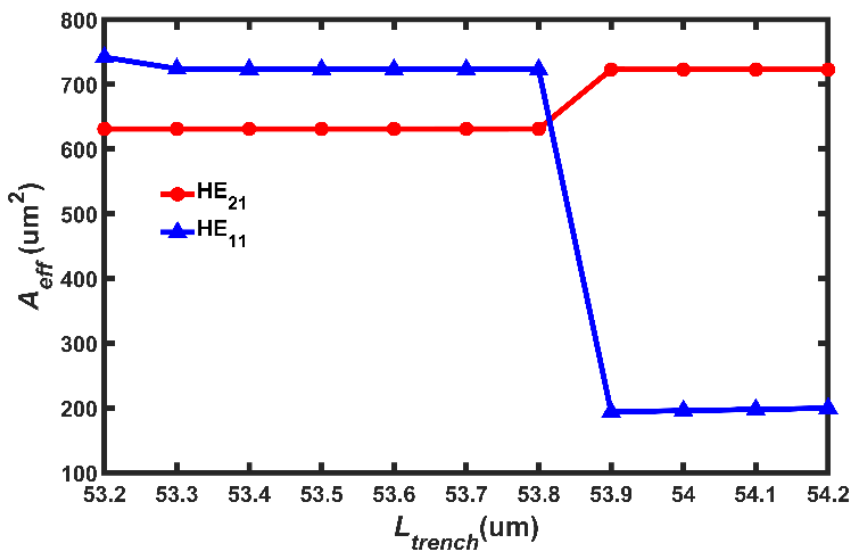

(a)

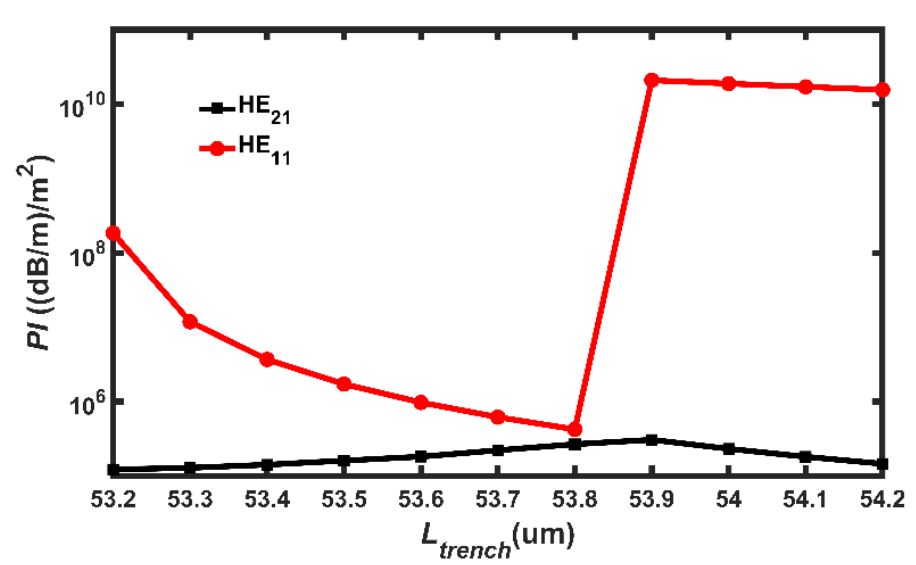

(b)

Figure 10. (a) The $N_{\text {eff }}$ of $\mathrm{HE}_{11}$ and $\mathrm{HE}_{21}$ varies with $L_{\text {trench }}$ (b) The PI of $\mathrm{HE}_{11}$ and $\mathrm{HE}_{21}$ varies with $L_{\text {trench }}$.

When $L_{\text {trench }}$ is $53.8 \mathrm{um}$, the influence of $\Delta n_{1}$ on $N_{\text {eff }}$ and PI is shown in Figure 11. Figure 11a shows that with the increase of $\Delta n_{1}, A_{\text {eff }}$ of the two modes firstly decreases, then increases, and finally stabilizes. In Figure $11 \mathrm{~b}$, the PI of the fiber decreases with the increase of $\Delta n_{1}$. This indicates that the larger the $\Delta n_{1}$, the better the comprehensive performance of the fiber. Due to the limitation of the manufacturing process, $\Delta n_{1}$ cannot be too large, and is usually set to 0.004 . 


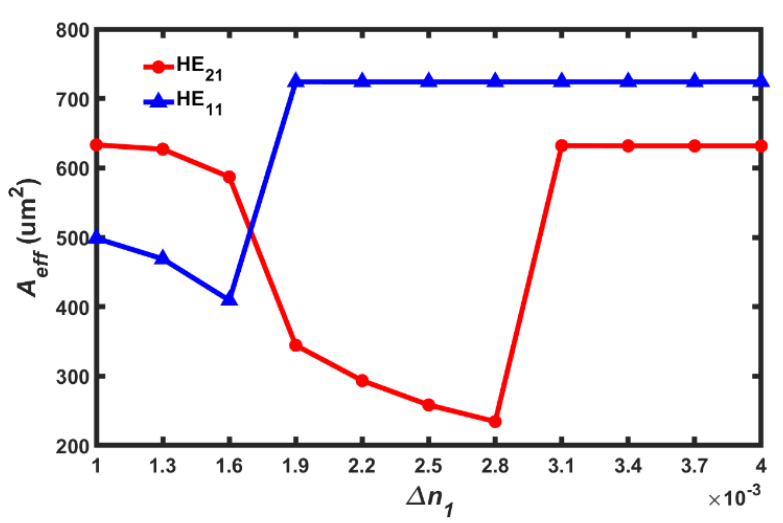

(a)

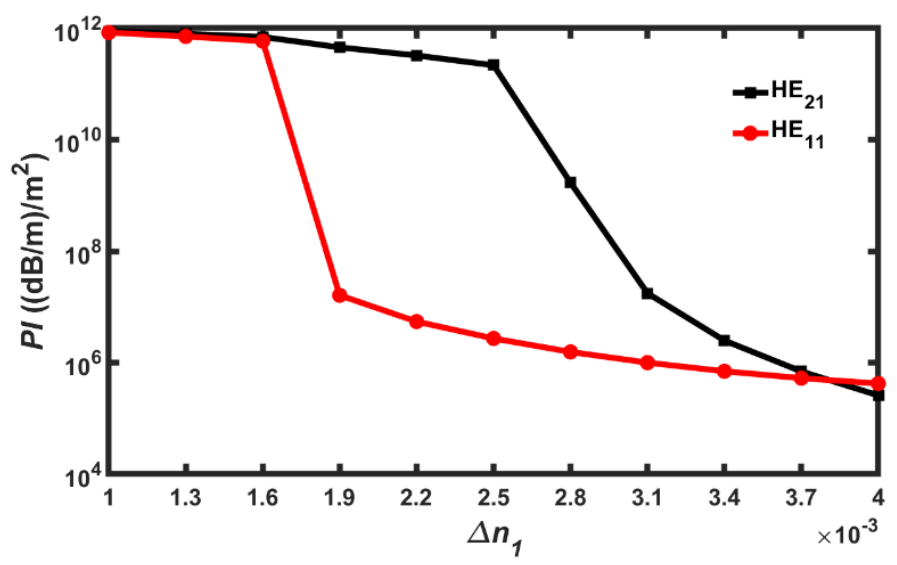

(b)

Figure 11. (a) The $A_{\text {eff }}$ of $\mathrm{HE}_{11}$ and $\mathrm{HE}_{21}$ varies with $\Delta n_{1} ;$ (b) the $B L$ of $\mathrm{HE}_{11}$ and $\mathrm{HE}_{21}$ changes with $\Delta n_{1}$.

In summary, the final optimized parameters are as follows: $\Lambda=14.5 \mathrm{um}, d=33 \mathrm{um}$, $\Delta n=0.0031, d_{\text {center }}=4.8 \mathrm{um}, \Delta n_{\text {center }}=0.002, W_{\text {trench }}=5.5 \mathrm{um}, L_{\text {trench }}=53.8 \mathrm{um}, \Delta n_{1}=0.004$.

\section{Conclusions}

A dual-mode TA-LBL-LMFA MCF with air hole structure is investigated in this paper. By removing the core on both sides of the traditional 19-core fiber, the fiber can destroy the circular symmetry structure of traditional 19-core fiber and cut off the high-order modes $\mathrm{TE}_{01}$ and $\mathrm{TM}_{01}$ with circular symmetry. Adding a circle of air holes at the periphery of the core area can confine the mode field in the core area effectively. Also, adding a trench that is lower than the refractive index of the cladding at the periphery of the air hole can effectively reduce the BL. The introduction of 10 cores into the silica region between the 19 cores increases the lateral coupling in the core area and increases the mode field area. In this way, a large mode field dual-mode transmission with low bending loss is realized. $\Lambda=14.5 \mathrm{um}, d=33 \mathrm{um}, \Delta n=0.0031, d_{\text {center }}=4.8 \mathrm{um}, \Delta n_{\text {center }}=0.002, W_{\text {trench }}=5.5 \mathrm{um}$, $L_{\text {trench }}=53.8 \mathrm{um}$, and $\Delta n_{1}=0.004$ are the optimized parameters. At this time, the $A_{\text {eff }}$ of the optical fiber $\mathrm{HE}_{11}$ can reach $2003.24 \mathrm{um}^{2}$. When the bending radius $R$ is $1 \mathrm{~cm}$, the bending loss $B L$ is $2.57 \times 10^{-3} \mathrm{~dB} / \mathrm{m}$. Potential applications are anticipated in the transmission of large-capacity optical communication systems and high-power lasers.

Author Contributions: Idea, conceptualization, and methodology, Y.L.; software simulation, formal analysis, investigation, resources, data curation, and writing-original draft preparation, R.J.; writingreview and editing, visualization, and supervision, Y.W.; project administration, funding acquisition, Z.L. All authors have read and agreed to the published version of the manuscript.

Funding: This research was funded by National Natural Science Foundation of China (Grant Nos. 61905062, 61927815, 62075056), China Postdoctoral Science Foundation (Grant No. 2020M670613), Hebei Postdoctoral Scholarship Project (B2020003026), Hebei Science and technology innovation strategy project (Grant No. 20180601).

Institutional Review Board Statement: Not Applicable.

Informed Consent Statement: Not Applicable.

Data Availability Statement: The data in this paper are available by contacting the corresponding author (ydlian@hebut.edu.cn).

Acknowledgments: The authors thank the Key Laboratory for providing access to all of the optical networks and advanced communication networks of the Ministry of Education (Beijing Jiaotong University) (Approval No. AON2019005).

Conflicts of Interest: The authors declare no conflict of interest. 


\section{References}

1. Desurvire, E.B. Capacity Demand and Technology Challenges for Lightwave Systems in the Next Two Decades. J. Light. Technol. 2006, 24, 4697-4710. [CrossRef]

2. Wang, F. Research on Equalization Technology of Mode Division Multiplexing System Based on Few Mode Fiber. Master's Thesis, University of Electronic Science and Technology of China, Chengdu, China, March 2020.

3. Cao, Y.; Shi, W.; Xu, G.; Sun, Y. Design of Bend-Resistant Large-Mode-Area Dual-Mode Photonic Crystal Fiber. Laser Optoelectron. Prog. 2015, 52, 84-90.

4. Cheo, P.K.; Liu, A.; King, G.G. A high-brightness laser beam from a phase-locked multicore Yb-doped fiber laser array. IEEE Photonics Technol. Lett. 2001, 13, 439-441. [CrossRef]

5. Zhang, Y.; Wen, W.; Yu, B.; Yuan, P. Technology of Slow Light in Photonic Crystal Waveguides. Laser Optoelectron. Prog. 2007, 10, 26-32.

6. Dai, L.; Li, T.; Jiang, C. Wideband ultralow high-order-dispersion photonic crystal slow-light waveguide. J. OSA B 2011, 28, 1622-1626. [CrossRef]

7. Baba, T. Slow light in photonic crystals. Nat. Photonics 2008, 2, 465-473. [CrossRef]

8. Saini, T.S.; Kumar, A.; Sinha, R.K. Triangular-core large-mode-area photonic crystal fiber with low bending loss for high power applications. Appl. Opt. 2014, 53, 7246-7251. [CrossRef] [PubMed]

9. Zheng, S.; Ren, G.; Lin, Z.; Jian, W.; Jian, S. Design and analysis of novel multilayer-core fiber with large mode area and low bending loss. Opt. Commun. 2014, 315, 317-323. [CrossRef]

10. Li, H.; Ren, G.; Yin, B.; Lian, Y.; Bai, Y.; Jian, W.; Jian, S. Modeling and optimized design of a parabolic-profile single-mode fiber with ultra-low bending loss and large-mode-area. Opt. Commun. 2015, 352, 84-90. [CrossRef]

11. Zheng, S.; Ren, G.; Lin, Z.; Jian, W.; Jian, S. A novel four-air-hole multicore dual-mode large-mode-area fiber: Proposal and design. Opt. Fiber Technol. 2013, 19, 419-427. [CrossRef]

12. Vogel, M.M.; Abdou-Ahmed, M.; Voss, A.; Graf, T. Very-large-mode-area, single-mode multicore fiber. Opt. Lett. 2009, 34, 2876-2878. [CrossRef]

13. Fini, J.M. Large-mode-area multicore fibers in the single-moded regime. Opt. Express 2011, 19, 4042-4046. [CrossRef]

14. Xia, C.; Bai, N.; Ozdur, I.; Zhou, X.; Li, G. Supermodes for optical transmission. Opt. Express 2011, 19, 16653-16664. [CrossRef]

15. Jin, W.; Ren, G.; Jiang, Y.; Wu, Y.; Xu, Y.; Yang, Y.; Shen, Y.; Ren, W.; Jian, S. Few-mode and large-mode-area fiber with circularly distributed cores. Opt. Commun. 2017, 387, 79-83. [CrossRef]

16. Ma, S.; Ning, T.; Lu, S.; Zheng, J.; Li, J.; Pei, L. Bending-Resistant Design of a Large Mode Area Segmented Cladding Fiber with Resonant Ring. J. Light. Technol. 2018, 36, 2844-2849. [CrossRef]

17. Wang, G.; Ning, T.; Pei, L.; Ma, S.; Zhang, J.; Zheng, J.; Li, J.; Wei, H.; Xie, C. A bending-resistant large mode area pixelated trench assisted segmented cladding fiber. Optik 2020, 203, 164024. [CrossRef]

18. Yang, M.; Lian, Y.; Wang, J.; Zhang, Y. Dual-Mode Large-Mode-Area Multicore Fiber with Air-Hole Structure. IEEE Photonics J. 2019, 11, 1-10. [CrossRef]

19. Jiang, Y.; Ren, G.; Lian, Y.; Liu, Y.; Liu, H.; Li, H.; Ren, W.; Jian, W.; Jian, S. Multilayer-core fiber with a large mode area and a low bending loss. Chin. Opt. Lett. 2016, 14, 120601. [CrossRef]

20. Ma, S.; Ning, T.; Li, J.; Zheng, J.; Wen, X.; Pei, L. Design and analysis of a modified segmented cladding fiber with large mode area. Opt. Laser Technol. 2017, 88, 172-179. [CrossRef]

21. Tong, Y.; Shuo, C.; Huiping, T. A bend-resistant low bending loss and large mode area two-layer core single-mode fiber with gradient refractive index ring and multi-trench. Opt. Fiber Technol. 2018, 45, 235-243. [CrossRef]

22. Yuqin, Z.; Yudong, L.; Yuhe, W.; Mengxin, Y.; Jingbo, W.; Nannan, L.; Yulei, W.; Zhiwei, L. Design and analysis of trench-assisted dual-mode multi-core fiber with large-mode-field-area. Appl. Opt. 2021, 60, 4698-4705.

23. Xie, X. Experimental Study of Bending Loss in Single-Mode Fiber. Master's Thesis, Beijing Jiaotong University, Beijing, China, June 2016. 